\title{
Practical Realism about the Self
}

\author{
Carolyn Dicey Jennings \\ University of California, Merced
}

(7041 words)

\begin{abstract}
In Explaining Attitudes, Baker argues that we should treat our everyday practices as relevant to metaphysical debates, resulting in a stance of realism with respect to intentional explanations. In this chapter I will argue that if one is going to be a practical realist about anything, it should be about the self, or the subject of attention. I will use research on attention combined with the stance of practical realism to argue in favor of a substantive self. That is, I will present an account of the self that directs and controls attention, in line with our everyday view of the self. I will contrast this account with what I call the "illusion view," which presents the self and its apparent causal power in the case of attention as an illusion. My account of the self will make use of several of Baker's ideas, including non-reductive materialism and broad supervenience.
\end{abstract}

\section{Introduction}

Baker's later writings on the self and her property constitution view inspired my own work on a brain-based account of the self, or the subject of attention (see Baker 2009, 2016 and Jennings 2012, 2020). While we differ on some of the details, we share a non-reductive materialist approach that takes as central the role of the body and its environment. In this chapter I wish to go further in support of my account of the self, using some of Baker's earlier work (e.g. Baker 1995). Namely, I will use her work on practical realism as further evidence in support of my view. This work takes seriously the commitments of our everyday interactions, which she sees as including a role for beliefs. More fundamental than our commitment to beliefs, however, is our commitment to the holders of those beliefs_-persons or selves. I will thus argue that if we should be practical realists about anything, it is the self, or the subject of attention. Along the way I address the opposing view, which I call the "illusion view"- the idea that the existence of a self with its own causal powers is an illusion. My account of the self, supported by some of Baker's reasoning, provides a remedy to such skepticism.

\section{Baker on Practical Realism}

In her early work, Baker espouses a theory that she dubs "Practical Realism." It is "practical" because it concerns our everyday practices (Baker 1995, 19). Specifically, it holds that we should be realists about the existence of that which is implied by our everyday practices, even in the absence of validation by the sciences (Baker 1995, 21). Baker focuses her discussion on the existence of beliefs, contrasting her position with what 
she calls "the standard view." According to the standard view, Baker says, beliefs are reducible to brain states; if a belief cannot be so reduced, then it doesn't exist (Baker 1995, 6). She claims, instead, that our everyday practices serve as independent evidence for beliefs. Moreover, this independent evidence supports an understanding of beliefs as not reducible to brain states.

Baker's description of the standard view is intended to capture the most popular theories in philosophy of mind at the time of writing. These are listed as including type and token identity theories, constitution theories, functionalism, eliminative materialism, and certain relational views (Baker 1995, 8-12). Baker sees such theorists as committed to the standard view because they embrace naturalism: they see the standard view as the only alternative to dualism, they see science as supporting the standard view, and they think the standard view is the only way to explain how beliefs can have causal power (Baker 1995, 12-17). Baker rejects these claims, while nonetheless embracing naturalism. She calls her own view "radical relationism," which she takes to be a type of "non-reductive materialism" (Baker 1995, 156).

Take, for example, what Baker calls "the most detailed attempt to provide an explanatory role for belief": Dretske's relational account (Baker 1995, 62). Dretske's view is a version of the standard view because beliefs are taken to supervene on states or properties of the brain (Baker 1995, 57); it is a relational view because beliefs have meaning only in virtue of their role in bringing about a behavior by indicating something (Baker 1995, 58). Despite its virtues, Baker finds Dretske's account to fail due to a vicious circularity. Specifically, in Baker's description, Dretske finds beliefs to have causal power because they have meaning, and he finds them to have meaning because of their causal role in behavior (Baker 1995, 59). For Baker, this is one example of how the standard view has failed to find a non-circular explanation of beliefs. Yet, she finds that instead of abandoning beliefs we should abandon the standard view, in favor of practical realism.

If we are practical realists - that is, if we are realists about the existence of that which is implied by our everyday practices - then we should accept the existence of beliefs, according to Baker. This is because our everyday practices depend on belief attributions, which are committed to the existence of beliefs. When we, for example, use a crosswalk to cross the street we are committed to the existence of nearby drivers' beliefs: the belief that we are in the crosswalk, that we have right of way, and that they should stop. If we were not committed to the existence of these beliefs, then it would be difficult to explain our behavior. For Baker, the commitments of these everyday practices trump our inability to explain the physical basis of belief; even if we can't make sense of belief within a naturalistic worldview, we should accept the existence of beliefs.

Further, Baker finds that our everyday practices support a radically relational understanding of belief. This form of relationism is "radical" because it rejects the microphysical reduction inherent in the standard view. 
Baker thinks we have focused on microphysical reduction due to a conflation of constitution with supervenience. That is, we think of beliefs as microphysically reducible because we believe they are constituted by brain states, and so must supervene on brain states. Baker argues forcefully against this idea using the concept of multiple realizability: certain processes or mechanisms can be realized in multiple ways, such that even if an instance of such a process or mechanism is constituted in a particular way it need not supervene on that particular constitution (Baker 1995, 132). Take the example of physical currency: the United States dollar may be constituted by paper, but it does not supervene on paper, since it might be constituted in other ways (e.g. plastic).

As with currency, Baker sees beliefs as multiply realizable. This is because "one's state of believing that $\mathrm{p}$ depends on global properties... of whole organisms" (Baker 1995, 22). In other words, beliefs are states held by persons, not their parts: "belief is a global state of a whole person, not of any proper part of the person, such as the brain" (Baker 1995, 153). We don't say that necks or knees believe, we say that people believe. We might hold that specific beliefs are constituted by specific parts of a person, such as specific neural circuits in the brain, while also holding that they could be constituted by other neural circuits.

Put another way, the reason that currency and beliefs are multiply realizable with respect to their constituent parts is that they concern phenomena at a different scale than those parts, that engage with other phenomena at their own scale. That is, Baker sees beliefs as relational, holding between persons and their environments. It is because beliefs are relational at this scale that they "do not supervene on local microstructure" (Baker 1995, 63). That is, they may be constituted by particular neural circuits, but they do not supervene on those circuits, since they have to do with the relationship between those circuits as part of a person and the environment of the person in question. As Baker sees it, constitution has to do with objects and their parts, whereas supervenience has to do with the properties of those objects, which may depend on other objects: thus, "supervenience relations (among properties) diverge from constitution relations (among things)" (Baker 1995, 132).

So, for Baker, beliefs may be constituted by brain states, but they are not reducible to brain states. This is because the distinctive properties of beliefs depend on the relationship of those brain states with other objects and states. This is what it means for beliefs to be held by persons in particular environments. This is a naturalistic view of beliefs, but one that differs significantly from the standard view that beliefs depend only on brain states; it is an early instance of externalism, the view that mental phenomena may depend on or be constituted by events that occur outside of the brain and body. 
Inspired by Baker, I apply her ideas to attention and the self. That is, I find that the self is constituted by brain states but is not microphysically reducible. I argue for this position below, first confronting an opposing position on the self: that it is an illusion. Like Baker, I see my project as an important remedy for skepticism, albeit in this case for skepticism about the existence of a self, rather than beliefs. I see practical realism about the self to be more basic than practical realism about beliefs, since beliefs are held by persons or selves. Thus, if we should be practical realists about anything, it is the self. I believe this coheres with Baker's own philosophical commitments, as I will explain below.

\section{Illusion View}

The illusion view, as I am calling it, has to do with the concept of a self with causal power. That is, it has to do with the concept of mental causation by a self. Many have argued that this is an illusion, in part due to empirical evidence. They argue that the self is a mental construct, and that there is no reason to think of the self as something that does things. Instead, as Baker puts it, this view is that "selves are illusory products of the brain" (Baker 2016, 8).

Take, for instance, Wegner and Wheatley's now classic paper on the experience of mental causation (Wegner and Wheatley 1999). They show that when two people have control over a process, a participant can be fooled as to how extensive their own role was in that process merely by inducing a thought that aligns with the outcome of that process. In Wegner and Wheatley's view, which is inspired by Hume, causation is inferred from the conjunction of two events that are close to one another in time, when other explanations of the "caused" event are not available. In the case of mental causation, we might infer that a thought that occurred before an action is a cause of that action if it is related to that action and other potential causes are not apparent. In their experiment on the topic, Wegner and Wheatley found that participants who were induced to have thoughts regarding a particular outcome were more likely to judge themselves as having a larger role in the process of bringing about that outcome, depending on the timing of that induction. Wegner and Wheatley think that in the normal case we mistake our conscious thoughts as being effective, when really only unconscious mechanisms have an impact on our behavior: "the real causal mechanisms underlying behavior are never present in consciousness. Rather, the engines of causation are unconscious mechanisms of the mind" (Wegner and Wheatley 1999, 490).

Wegner and Wheatley are likely inspired, in part, by Libet's research a decade earlier (Libet 1985). Namely, Libet found a delay between unconscious mechanisms that predict our choices and our own awareness of making those choices: "the brain 'decides' to initiate or, at least, to prepare to initiate the act before there is any reportable subjective awareness that such a decision has taken place" (Libet 1985, 536). Given the ability 
for others to predict our choices before we are subjectively aware of them, it seems reasonable to see unconscious mechanisms as having the real causal power here. Yet, some have argued that the apparent neural tendencies that these predictions are based on are an artefact of the data processing in this study: Libet lines up the neural oscillations prior to the act, and background neural oscillations tend to ramp up before an act of this kind (i.e. a "spontaneous" act that is allowed to occur only when background oscillations have ramped up in this way; cf. Schurger, Sitt, and Dehaene 2012). Further, Libet found that these tendencies can be vetoed by the participant (Libet 1985; see also Schultze-Kraft, et al. 2016). So Libet's finding shows that there are unconscious influences on our choices before we make them, but not that our conscious experience is ineffectual. Thus, even if we align the self with consciousness, Libet's findings do not show us that the self does not have causal power. For that we would need further evidence, such as that put forward by Wegner and Wheatley.

From within philosophy, Metzinger likewise argues that the self is a construct, drawing in part on Wegner and Wheatley's findings (Metzinger 2004, 406). For Metzinger, this illusion extends to all phenomenal objects: "what you subjectively experience as an integrated object possessing a transtemporal identity (e.g., the book you are holding in your hand) is being constituted by an ongoing process" (Metzinger 2004, 23). Similarly, he thinks we reify the self in our experience, seeing it as something substantive, rather than something we are in the process of creating. Yet, the illusion of self is different from that of other objects, Metzinger argues, since the self does not exist: "There is no one whose illusion the self could be, no one who is confusing herself with anything" (Metzinger 2004, 634).

The existence of the self is rejected by Metzinger, in part, because of the homunculus problem posed by Dennett (Metzinger 2004, 307). As Schneider puts it, "Dennett is clearly opposed to... theories purporting to explain cognitive capacities by generating a decomposition that ultimately boils down to an internal agent, or homunculus... the consciousness of the homunculus would itself need to be explained, so this sort of explanation is circular" (Schneider 2007, 317). In other words, posing a new internal agent cannot by itself help us to explain phenomena such as conscious perception, since the problem is how any agent can consciously perceive, including an internal one. But note that this problem does not show that the self does not exist, or even that an "internal agent" does not exist, only that introducing new selves does not by itself explain other phenomena.

In arguing against the existence of a self with causal power, Dennett goes further than the homunculus problem, citing evidence from split brain studies: “A central clue comes from the sort of phenomena uncovered by Michael Gazzaniga’s research. According to Gazzaniga's view, the mind is not beautifully unified, but rather a problematically yoked together bundle of partly autonomous systems" (Dennett 1992, 
111). Instead of saying that a new self has been created in the process of severing the corpus callosum in these patients, he argues that it makes more sense to see these studies as revealing that a person's "center of narrative gravity," or self-concept, can be split in two (see also Nagel 1971). Dennett argues that split-brain phenomena reveal that the brain is normally disunified, and that a unified self is an illusion. Yet, these patients also retain some unity, as Dennett illustrates through pain: "pain stimuli go to both hemispheres," so a painful stimulus is easily reported by these patients, regardless of the side of stimulation (Dennett 1992, 113). In fact, more recent work has claimed that "severing the cortical connections between hemispheres splits visual perception, but does not create two independent conscious perceivers within one brain" (Pinto, et al. 2017, 1231). ${ }^{1}$ Thus, we might simply say that the unity of selfhood is relative and that split-brain patients have a relatively disunified self, rather than two selves, avoiding the metaphysical problem (see also Schechter 2014).

In my view, we have ample evidence for the existence of a self that isn't well countered by the above. Like any substantive thing, we can be wrong about the self, mistaking something as due to the self when it is due to someone or something else, which I think is the best explanation of Wegner and Wheatley's findings. Further, there is a way in which our understanding of the self is constructed, just as our understanding of other substantive things (e.g., this book) is constructed; This does not mean that the self is constructed by us, anymore than other substantive things are constructed by us, which I think is the best way of responding to Metzinger. Finally, the self can be more or less disunified, but this doesn't by itself show that there isn't a self, against the claims of philosophers such as Dennett. We might, for instance, pin the question of whether there is a self on whether there are non-reducible causal powers attributable to the self, rather than on whether there is sufficient unity. In the next section I will discuss the evidence I take to point to the existence of a substantive self, later comparing this to Baker's own view of the self.

\section{The Subject of Attention}

In line with Baker's stance of practical realism regarding beliefs, I see a case for practical realism regarding the self. Namely, the existence of the self is assumed in the way we interact with others. Specifically, the existence of a self with causal powers is so assumed. Take, for instance, our hesitation at the crosswalk, even when we obviously have right of way, and even when we are sure the driver has seen us-we hesitate because we are unsure what the driver will do with this information. We treat this as up to the driver, to a certain extent. And, if the driver chooses to speed on through, we might blame them for their behavior, perhaps even shout at them. This is because we think of them as responsible for this choice, and we want to have an impact on

\footnotetext{
${ }^{1}$ Interestingly, those born without a corpus callosum likewise reveal that information can still be shared across the hemispheres in its absence, although perhaps due to physiological changes not present in the split-brain case (Tovar-Moll, et al. 2014).
} 
their future choices. We might think of the driver's beliefs as having an impact on their decision, but we also think there is more to their decision, that it depends on the person, or self, in question.

The everyday assumption of the existence of a self with causal powers is especially evident, I think, in the way we think and talk about attention. Attention is said to be something that can be both "paid" and "grabbed." It is, for example, "paid" in the classroom but "grabbed" by advertising. The distinction between one's attention being paid or grabbed depends on a self who is either doing the paying or whose attention is being grabbed. In both cases, attention is a way of bringing about behavioral change. In one case, we pay attention to change our behavior in a way that aligns with our goals; in the other case, our behavior is changed by others in order to better align with theirs. So the assumption of a self that can pay attention is the assumption of a self with causal power.

Beyond speech, our everyday practices distinguish between attention that is driven by the self and attention that is driven by external forces. When we want to grab attention, we resort to fast movements, bright colors, and loud sounds. Social media use, for example, the sudden onset of red notifications. When we want someone to pay attention we try to be interesting to them, or to show them why they should be interested. Teachers do this, for example, by connecting classroom material with everyday life. We take something extra to be involved in the latter case due to the assumption that we are interacting with a self, who has the power to control attention. We tailor our behavior toward someone's attention depending on whether we need to involve the self or undermine it. In this way, our everyday practices assume the existence of a self.

Philosophers and scientists have long recognized that attention might be the place to look for mental causation by the self and have debated whether attention truly is evidence of a self. This comes up in a dispute between Bradley and James over one hundred years ago, and between Indian philosophers a couple millennia before that (Jennings 2020; Ganeri 2017; Jennings in press). In contemporary scientific debates, mental causation by the self is replaced with "executive control," and the question is whether there is a plausible account of attention based in executive control that is not reducible to local neural interactions. As I argue in my book, there is such an account: attention is directed by the self when the neural firing that occurs over a larger region and over a longer time period cumulates into oscillations with higher amplitudes than those of feedforward processing, such that the higher frequency, lower amplitude oscillations have power over the organism's behavior only at certain intervals in the lower frequency, higher amplitude oscillations (i.e. in the troughs; Jennings 2020). ${ }^{2}$

\footnotetext{
2 This is closely related to Thomas Hills' account of "neurocognitive free will," except that his account involves a construct of self, rather than a true self (Hills 2019).
} 
To draw out this idea a bit more, my view is that when attention benefits from executive control that this is best explained by a whole-brain phenomenon. This aspect of attention is typically picked out by feedback from the deeper layers of the prefrontal cortex, which requires a delayed response (Connor, et al. 2004; Lakatos, et al. 2005; Wilken, et al. 2009; Baluch and Itti 2011). This delayed response allows for input from a broader spatio-temporal range of neural activity: more areas of the brain, covering a larger spatial area, and over a longer time span. Due to the scale-free relationship between neural oscillations that maintains smaller amplitudes for higher frequencies, a process that allows for input from a broader spatio-temporal range of neural activity will correspond with neural oscillations of larger amplitudes (see, e.g., Buzsáki \& Draguhn 2004). This then allows for such a process to control local, feedforward processing. That is, local feedforward processing would not be able to have an impact on behavior unless it occurred at certain time intervals, due to the larger amplitude of the feedback oscillations (Lakatos, et al. 2008). In fact, when attention benefits from executive control it has been found to correspond with lower frequency oscillations (Buschman and Miller 2007).

The self corresponds, in this picture, to the pattern of wave activity that occurs for longer intervals and larger regions of the brain, sometimes called "global" brain activity. I see this pattern as comprised of the tendencies and interests of the organism. Insofar as this pattern is responsible for the direction of attention, I call it the "subject of attention." I think that this understanding of the self can satisfy the assumptions of our everyday practices, described above.

If the subject of attention corresponds with the whole-brain pattern of wave activity, one might wonder how it has control over local neural processing. It might seem absurd, or even paradoxical, to claim that something can have control over itself in this way. Yet, I think we can make sense of this using some conceptual tools developed by others, such as machretic determination and contextual emergence. These tools differentiate the view on offer from the circular causation of strong emergence and the causal collapse of weak emergence, as I explain below.

Contextual emergence is a concept developed by Harald Atmanspacher (2007), who contrasts it with forms of emergence that rely on supervenience. Supervenience is a relationship between a whole and its parts such that changes in the whole depend on changes in its parts. One might thus think of any causal power of the whole as being driven by the parts. Contextual emergence is a case of a whole with causal power that is not reducible to its parts, a denial of supervenience.

Atmanspacher situates contextual emergence as in between a "weak" emergence view, in which a whole merely appears to have properties that go beyond those of its parts, and a "strong" emergence view, in which 
the parts are neither necessary nor sufficient for the whole that emerges from them. Both strong and weak emergence have been argued to have significant philosophical problems. In the case of strong emergence, the main problem is that it seems to rely on a form of causation that is circular, such that the parts bring about the whole that causes changes to its parts. In the case of weak emergence, the main problem is that any causal power is reducible to the parts, and so the whole seems metaphysically unnecessary (see the discussion on Kim, below). In contextual emergence, the parts are necessary for the whole that emerges from them, but not sufficient, since emergence only occurs in a particular context.

Similarly, in my view, the self is the sort of thing that relies on context. The self is a set of interests, or tendencies to seek out and respond to stimuli in a particular sort of way. Only embodied beings have interests. Thus, it makes sense to suppose the context necessary for the self to be the body. After all, the body is necessary to provide the stimuli that interests govern, and the body has limitations that make governance necessary. But I think it is this last thing, in particular, that is required for the emergence of the self: the constraints faced by a body in a world of its approximate spatio-temporal scale. Only in such a scenario would you have a self, or a set of interests with its own causal power.

In this way of thinking, the parts of the self are the parts of the pattern of neural oscillations, or individual neural oscillations that correspond with individual interests. So a particular pattern of neural oscillations is necessary for the self, but that pattern is not sufficient for the self. To bring about something with its own causal power, like a self, the pattern of neural oscillations must be part of a body; the self exists only so long as there is a body with constraints that the self can serve. The self thus does not supervene on these neural oscillations but is nonetheless intimately connected to them.

The self, in my view, is a solution to the problem of conflicting interests-when two or more interests, or tendencies to seek out and respond to stimuli in a particular way, come into conflict, the self is what resolves that conflict for the good of the organism (see Jennings 2017). The self is, in this picture, the set of all interests, or tendencies to seek out and respond in a particular way to stimuli. So the resolution of conflict occurs through a weighing of all interests or tendencies, such that one is supported at the expense of the other because it is a better fit with the rest. We can understand this process through the concept of machretic determination.

Machretic determination was developed by Carl Gillett (2016) to explain how an emergent entity might control its parts in a non-causal way. Specifically, an emergent entity might determine the contribution of its parts insofar as the parts are only able to make that contribution if they are brought into a relationship that allows for a new property at the level of the emergent entity. So the emergent entity does not cause the parts to have 
that relationship, but the emergent entity can control the parts by determining that they will only be part of an emergent entity if they have that relationship. Gillett encourages us to think of the directional forces of parts that must all be lined up in a particular way to get a new, larger force at the level of the whole. Thus, the parts make up that larger force only when lined up in that way, and so the whole "controls" the contributions of its parts.

Applying this to the view of self on offer, I consider the self to have power insofar as it resolves the conflicts between its component interests. Those interests are thus only part of the self insofar as they "line up" with one another-the self "machretically determines" the contributions of its component interests. This need not be seen as a causal power, since the self need not have causal power over its parts to determine which parts are component parts. Yet, this control can be a way for the self to exert causal power: by controlling its parts, the self alters the landscape of neural activity, and by altering the landscape of neural activity, the self alters bodily responses to stimuli. The self thus has causal power over the body through machretic determination over its parts. (I discuss this view at greater length in Jennings 2020.)

That a self with causal power is responsible for resolving conflicting interests through attention is implied, I think, by our everyday understanding of the self and attention. In this way my approach is one of practical realism with respect to the self. Further, it is a more basic practical realism than Baker's since beliefs are held by persons or selves. Yet Baker's own view of the self was somewhat different, as I will explain in the next section.

\section{Baker's "self" and property constitution}

In putting forward his illusion view of the self, Metzinger cites Baker as inspiration (Metzinger 2004, 395). Baker had, several years prior, argued that the existence of a first-person perspective challenges reductive materialism (Baker 1998). To answer this challenge, Metzinger provided a reductive materialist account of the first-person perspective, which Baker called "the most comprehensive theory of the first-person perspective that I know of' (Baker 2007, 204). Yet Baker goes on to argue that his illusion view is incoherent, in part because the illusion would have to be held by something, such as a subject (recall Metzinger's claim that "there is no one whose illusion the self could be..."). Further, in her view, the "experience of being a conscious subject is evidence that I am a subject, and this evidence overwhelms any possible evidence that I may have for any scientific theory to the contrary" (Baker 2007, 221). That is, much like Moore's two hands, Moore's certainty of which cannot be undermined by something of which he is less certain, Baker's certainty of being a subject cannot be undermined by the commitment to reductive materialism, or other positions of which she has less certainty (Moore 1939). 
Baker's way of talking about the subject is, again, through the notion of a first-person perspective. As she sees it, a weak first-person perspective is one in which experience is perspectival, but a strong first-person perspective is one that is also conceptualized as such, and it is the latter that is essential to being a person. In Baker's view, the first-person perspective is relational, much like beliefs, which is why it doesn't fit well with reductive materialism: it is "a perspective from which one thinks of oneself as an individual facing a world, as a subject distinct from everything else" (Baker 2007, 203). Her view is thus also externalist, in that a firstperson perspective would not exist without objects or persons apart from the subject.

One distinction between Baker's view and my own is that she does not think a first-person perspective requires a self: "the idea of a self is much richer than the idea of a first-person perspective. A self is the locus of personal integrity and coherence, but such a self is not required for a first-person perspective" (Baker 1998, 342). She uses the example of someone with brain damage trying to discover who they are, which she describes as a case of first-person perspective without a "coherent and comprehensive" self. As I say above, a self might be more or less unified, and a relative lack of unity may not point to the absence of self. Further, the example in question appears to pertain to an absence of memory and one's conception of self, and not necessarily an absence of self. In fact, Baker closes that passage by claiming that a first-person perspective is necessary, but not sufficient, for "an idea of a self." As I said in response to the Wegner and Wheatley experiment, we should separate the self from any construct, model, or idea of the self. In my view, a construct, model, or idea of the self is based on an actual self, and it aids us in recognizing the impact of our own self on our behavior, as well as the impact of other selves on their behavior.

Baker has a similar view in the vicinity regarding persons, which, for her, are necessarily embodied: "When I deny that there are selves, what I deny is that the bearers of psychological properties are proper parts of persons or animals" (Baker 2016, 14). (Recall also her earlier claim: "belief is a global state of a whole person, not of any proper part of the person.”) Given that my own, brain-based account of the self also requires constraints at the level of the body, it might be difficult to find light between our views. Yet, I essentially base the self in the brain, seeing it as constituted by patterns of brain activity, whereas Baker sees a person as constituted by the body. So Baker and I diverge on certain points, while sharing some important commitments.

The most central of those commitments is to non-reductive materialism. As Baker makes clear, she finds the existence of a first-person perspective to challenge reductive naturalism. She urges us to embrace nonreductive materialism, in its stead. She helpfully demonstrates in a book chapter on the topic how such a 
perspective might establish the possibility for mental causation, against Kim's influential arguments to the contrary (Baker 2009; Kim 2009).

Kim argues that we have to choose between a reductive physicalist account of the mind and a dualist account, since a supervenience-based account is untenable (see, e.g., Kim 2009). He claims that a supervenience-based account is untenable because mental causation, as distinct from physical causation, is untenable. Without causal power over the physical, the supervening entity either collapses into a reductive physical one or is relegated to the role of Huxley's whistle: an epiphenomenon, separate from the physical without influencing it (Huxley 1874). Mental causation is untenable due to the causal closure of the physical, or the view that all physical events have a sufficient physical cause. Since all physical events have a sufficient physical cause, any additional mental cause would result in overdetermination of physical events, which Kim rules out as absurd given the required number of such events.

While Kim's argument may be used against supervenience-based accounts, I have argued so far for a different perspective on the mind. In this perspective, the emergent self does not supervene on its microphysical basis. Kim seems to have been unaware of this possibility, claiming that all accounts of emergence are forms of supervenience. For this reason, Kim's argument fails. Baker was the first, I believe, to make this point.

According to Baker, Kim's argument depends on at least one false supposition (Baker 2009). That is, Kim supposes that if the mental is not reducible to its microphysical basis and yet has causal power over, say, other mental events, then it must do so through downward causation. This is because the mental event in question must itself have a microphysical basis it supervenes over, so to change the mental event the mental would have to change the event's microphysical basis, thus requiring downward causation from the mental to this microphysical basis. As I argue above, contextual emergence does not rely on supervenience, so this inference does not hold. Baker uses the language of "property constitution" to make the point: "A property's constituter on a given occasion may be a proper part of a supervenience base for the property, but the constituting instance... does not suffice for the constituted instance" (Baker 2009, 121). Certain circumstances are necessary to bring about the emergent property, just as a certain context is necessary in contextual emergence.

Yet, as Baker also points out, this may only be a denial of local supervenience; global supervenience may yet hold. This is, in fact, what allows Baker to hold onto the causal closure of the physical. That is, it may be that all cause and effect within the physical world is contained, while the causes and effects regarding a particular object within that world are not: “The supervenience base will be very broad—-too broad to be specified or to 
be useful in explanation—-but it will be metaphysically sufficient for the constituted property instance" (Baker 2009, 123).

In the same vein, the subject of attention might be thought to deny local, but not global supervenience, countering Kim's argument that an emergent entity could not have causal power so long as we accept the causal closure of the physical. The subject of attention could be an emergent entity with causal power without violating that principle, in line with Baker's reasoning. In my view, this is further support for a stance of practical realism regarding the self, or the subject of attention.

\section{Conclusion}

I have argued for the existence of a self, or a brain-based subject of attention, to counter a skeptical position with regard to the self- the illusion view. Baker found herself in the vicinity of this view, denying the existence of a self while embracing the existence of persons and their first-person perspectives. Yet our views are closely aligned. We each embrace non-reductive materialism, finding persons or selves to depend on bodies in a world. For Baker, persons are constituted by bodies, whereas I see selves as constituted by brain activity. Baker nonetheless joins me in resisting those, like Metzinger and Dennett, who deny the existence of a self, calling it an illusion.

Against the illusion view, I have proposed that we use Baker's earlier work, on practical realism, to support the existence of a substantive self. While Baker used practical realism to support her account of beliefs, I see the self as more fundamental than beliefs, since beliefs are held by persons or selves. Further, the same argumentative tactics used by Baker in favor of beliefs can support the self: the existence of a self is assumed in our everyday interactions with others. Thus, we should not reject the self simply because we do not yet have a scientific understanding of the phenomenon. Instead, we should see its use in everyday life as evidence for its existence. This, together with brain evidence as to the causal power of the self over attention, should be enough to stymie such skepticism, at least for now. 


\section{References}

Atmanspacher, H. (2007). Contextual emergence from physics to cognitive neuroscience. Journal of Consciousness Studies, 14(1-2), 18-36.

Baluch, F. and Itti, L. (2011). Mechanisms of top-down attention. Trends in Neurosciences, 34(4):210-24.

Baker, L. R. (1995). Explaining Attitudes: A Practical Approach to the Mind. Cambridge University Press.

Baker, L. R. (1998). The first-person perspective: a test for naturalism. American Philosopbical Quarterly, 35(4).

Baker, L. R. (2007). Naturalism and the first-person perspective. In: Gasser, G. (ed.) How Successful is

Naturalism? Ontos-Verlag.

Baker, L. R. (2009). Non-reductive materialism. In: McLaughlin, B., Beckermann, A., \& Walter, S. (eds.) The Oxford Handbook of Philosophy of Mind. Clarendon Press.

Baker, L. R. (2016). Making sense of ourselves: self-narratives and personal identity. Phenomenology and the Cognitive Sciences, 15(1), 7-15.

Buschman, T. J. and Miller, E. K. (2007). Top-down versus bottom-up control of attention in the prefrontal and posterior parietal cortices. Science, 315(5820):1860-2.

Buzsáki, G., \& Draguhn, A. (2004). Neuronal oscillations in cortical networks. Science, 304(5679), 1926-1929. Connor, C. E., Egeth, H. E., and Yantis, S. (2004). Visual attention: Bottom-up versus top-down. Current Biology, 14(19):R850-2.

Dennett, Daniel C. (1992) The self as a center of narrative gravity. In: F. Kessel, P. Cole and D. Johnson (eds.) Self and Consciousness: Multiple Perspectives. Hillsdale, NJ: Erlbaum.

Ganeri, Jonardon (2017). Attention, Not Self. Oxford University Press.

Gillett, C. (2016). Reduction and Emergence in Science and Philosophy. Cambridge University Press.

Hills, T. T. (2019). Neurocognitive free will. Proceedings of the Royal Society B, 286(1908), 20190510.

Huxley, T. H. (1874). On the hypothesis that animals are automata, and its history.

Jennings, C. D. (2012). The subject of attention. Synthese, 189(3), 535-554.

Jennings, C. D. (2017). I attend, therefore I am. Aeon. Retrieved from: https://aeon.co/essays/what-is-theself-if-not-that-which-pays-attention

Jennings, C. D. (2020). The Attending Mind. Cambridge University Press.

Jennings, C. D. (in press). Too much attention, too little self? Philosophy and Phenomenological Research.

Kim, J. (2009). Mental causation. In: McLaughlin, B., Beckermann, A., \& Walter, S. (eds.) The Oxford

Handbook of Philosopby of Mind. Clarendon Press. 
Lakatos, P., Shah, A. S., Knuth, K. H., Ulbert, I., Karmos, G., and Schroeder, C. E. (2005). An oscillatory hierarchy controlling neuronal excitability and stimulus processing in the auditory cortex. Journal of Neurophysiology, 94(3):1904-11.

Lakatos, P., Karmos, G., Mehta, A. D., Ulbert, I., \& Schroeder, C. E. (2008). Entrainment of neuronal oscillations as a mechanism of attentional selection. Science, 320(5872), 110-113.

Libet, B. (1985). Unconscious cerebral initiative and the role of conscious will in voluntary action. Behavioral and Brain Sciences, 8(4), 529-539.

Metzinger, T. (2004). Being No One: The Self-Model Theory of Subjectivity. MIT Press.

Moore, G. E. (1939). Proof of an external world. In: Epistemology: An Anthology, 24-26.

Nagel, T. (1971). Brain bisection and the unity of consciousness. Synthese, 22(3):396-413.

Pinto, Y., Neville, D. A., Otten, M., Corballis, P. M., Lamme, V. A., De Haan, E. H., ... \& Fabri, M. (2017). Split brain: divided perception but undivided consciousness. Brain, 140(5), 1231-1237.

Schneider, S. (2007). Daniel Dennett on the nature of consciousness. In: The Blackwell Companion to Consciousness, 313-324.

Schechter, E. (2014). Partial Unity of Consciousness: A Preliminary Defense. In: Bennett, D. and Hill, C. (eds.) Sensory integration and the unity of consciousness. MIT Press.

Schurger, A., Sitt, J. D., \& Dehaene, S. (2012). An accumulator model for spontaneous neural activity prior to self-initiated movement. Proceedings of the National Academy of Sciences, 109(42), E2904-E2913.

Schultze-Kraft, M., Birman, D., Rusconi, M., Allefeld, C., Görgen, K., Dähne, S., ... \& Haynes, J. D. (2016).

The point of no return in vetoing self-initiated movements. Proceedings of the National Academy of Sciences, 113(4), 1080-1085.

Tovar-Moll, F., Monteiro, M., Andrade, J., Bramati, I. E., Vianna-Barbosa, R., Marins, T., ... \& Moll, J. (2014). Structural and functional brain rewiring clarifies preserved interhemispheric transfer in humans born without the corpus callosum. Proceedings of the National Academy of Sciences, 111(21), 7843-7848.

Wegner, D. M., \& Wheatley, T. (1999). Apparent mental causation: Sources of the experience of will. American Psychologist, 54(7), 480.

Wilken, P., Bayne, T. J., and Cleeremans, A. (2009). The Oxford Companion to Consciousness. Oxford University Press. 